\title{
O PAPEL SOCIAL DO MICROCRÉDITO: ESTUDO SOBRE 0 PROJETO CDD - CIDADE DE DEUS
}

\author{
THE SOCIAL ROLE OF MICROCREDIT: STUDY ON THE CDD - CIDADE DE DEUS PROJECT \\ EL PAPEL SOCIAL DEL MICROCRÉDITO: ESTUDIO SOBRE EL PROYECTO CDD - CIDADE DE DEUS
}

\section{RESUMO}

0 presente estudo propõe-se a compreender como o programa de microcrédito implementado na Cidade de Deus está contribuindo para a diminuição da pobreza no segmento da população excluída pelo mercado bancário tradicional. Para tal, destacam-se dois aspectos: um, de cunho social - a busca do microcrédito pela população pobre -- e outro, de cunho econômico - que aborda a autossustentabilidade financeira do programa. Foi empreendido um estudo qualitativo com pesquisa de campo e entrevistas semiestruturadas com microempreendedores locais, representantes de instituições financeiras e demais entidades que proporcionam crédito na comunidade. Os resultados obtidos demonstram que ainda existem entraves que dificultam o acesso dos mais pobres aos recursos do microcrédito e que a sustentabilidade financeira das instituições tem norteado as decisões quanto aos beneficiários destes recursos.

PALAVRAS-CHAVE: Microcrédito, inclusão social, políticas públicas, banco comunitário, Cidade de Deus.

Vera Lúcia de Aguiar Kelly ${ }^{1}$

verapa@uol.com.br

ORCID: 0000-0001-6404-3251

Ana Carolina Pimentel Duarte da Fonseca ${ }^{1}$

anafonseca@facc.ufri.br

ORCID: 0000-0003-0255-7569

Fernanda Filgueiras Sauerbronn'

fernanda.sauerbronn@facc.ufrj.br

ORCID: 0000-0002-7932-2314

${ }^{1}$ Universidade Federal do Rio de Janeiro, Programa de Pós-Graduação em Ciências Contábeis, Rio de Janeiro, RJ, Brasil

Submetido 24.03.2017. Aprovado 24.09.2018

Avaliado pelo processo de double blind review.

DOI: http://dx.doi.org/10.12660/cgpc.v24n77.67268 


\section{ABSTRACT}

The present study aims to understand how the microcredit program implemented in Cidade de Deus sought is contributing to reduce poverty in the segment of the population excluded by the traditional banking sector. To this end, two aspects are highlighted: one with a social aspect - the search by the poor population for microcredit; and another one - economic-oriented addressing the financial selfsustainability of the program. Semi-structured interviews were carried out with local micro-entrepreneurs, representatives of financial institutions and other entities, which provide credit in the community. The results obtained show that there are still barriers that hinder access of the poor to microcredit resources and that the institutions' financial sustainability have guided the decisions on the beneficiaries of these resources.

KEYWORDS: Microfinance, social inclusion, public policies, microfinance institutions, Cidade de Deus/ Brazil.

\section{RESUMEN}

Este estudio busca comprender como el programa de microcrédito en Cidade de Deus trató de atender las necesidades de un segmento de la población excluido del mercado de la banca tradicional. Para esto, se destacan dos aspectos: uno, de carácter social -la búsqueda del microcrédito por la población pobre y otro, de carácter económico - que aborda la autosostenibilidad financiera del programa. Se realizaron entrevistas semiestructuradas con los microempresarios locales, representantes de instituciones financieras y otras entidades que proporcionan credito en la comunidad. Los resultados obtenidos muestran que todavía existen barreras que dificultan el acceso de los pobres a los recursos de microcrédito y que la sostenibilidad de la institución ha guiado las decisiones sobre los beneficiarios de estos recursos.

PALABRAS CLAVE: Microcrédito, inclusión social, políticas públicas, institución de microfinanzas, Cidade de Deus/Brasil.

\section{INTRODUÇÃO}

A inclusão social e o combate à pobreza por meio do microcrédito é um tema recorrente principalmente quando são analisadas as políticas públicas implementadas na América Latina desde o início do séc. XXI (Gonzalez, Porto, \& Diniz, 2017; Zouain \& Barone, 2007). O desenvolvimento desse tema insere-se em um contexto que compreende as políticas públicas como tendo o objetivo de ampliar e efetivar direitos de cidadania gestados em lutas sociais e que, portanto, passam a ser reconhecidos institucionalmente (Rigo, França Filho \& Leal, 2015).

Conforme pesquisa realizada pela Organização Internacional do Trabalho (OIT), divulgada em 2015, 60,7\% dos profissionais no mundo não possuem nenhum tipo de vínculo empregatício, ou seja, atuam em micronegócios próprios (Gerbelli, 2015). Este é um dos motivos pelos quais a geração de trabalho e renda por meio dos pequenos empreendimentos locais vem ganhando consistência no mundo, mas com maior empenho nos países em desenvolvimento e de economia periférica (Ali, Hatta, Azman, \& Islam, 2017).

Nesse sentido, Diniz (2010) ressalta que tem ocorrido, em escala global, o crescimento dos mercados microfinanceiros, passando o microcrédito a ser reconhecido como meio de geração de renda e diminuição da pobreza em países em desenvolvimento.

Vale destacar que existem atualmente cerca de 10 mil instituições de microfinanças no mundo (Kim, 2017) que variam em tamanho e abordagem (Armstrong, Ahsan, \& Sundaramurthy, 2017). Como reflexo da importância dada ao tema, a ONU instituiu 2005 como o Ano Internacional do Microcrédito, atribuindo, 
no ano seguinte, o Prêmio Nobel da Paz ao professor de economia Muhammad Yunus, pelas suas iniciativas pioneiras na área, e ao Graamen Bank (instituição fundada por ele).

De acordo com Yunus (2009 apud Polato, 2013), "a sociedade nunca havia dado chance a essas pessoas. Elas pegaram o dinheiro e assumiram riscos. Todos podem ser empreendedores[...]".

Notadamente, tem surgido na recente literatura internacional sobre microcrédito uma onda de críticas sobre a eficácia desse serviço na redução de situações de pobreza. Dentre as críticas efetuadas pelos autores, destacam-se quatro pontos que não devem ser negligenciados: destinação dos recursos do microcrédito a beneficiários que não fazem parte do público-alvo (indivíduos classificados como os mais pobres dos pobres (Navajas, Schreiner, Meyer, Gonzalez-Vega, \& Rodriguez-Meza, 2000); direcionamento dos recursos, pelo público mais carente, para suas necessidades diárias, ao invés de alocá-los em investimentos produtivos para iniciar ou expandir um negócio (Fafchamps, McKenzie, Quinn, \& Woodruff, 2014); retorno esperado para o crédito é baixo devido à falta de capacitação, de conhecimento e de educação financeira dos microempreendedores (Birochi \& Pozzebon, 2016); perigos do endividamento às IMF's e surgimento de uma geração de empreendedores pobres e superendividados (Hulme, Dichter \& Harper, 2007; Ali et al., 2017; Loubere, 2016). Tais críticas têm servido de contraponto a abordagens otimistas sobre o papel social do microcrédito.

No contexto brasileiro, há um espaço significativo para o setor de microfinanças, con- siderando que o país possui 10,27 milhões de pessoas vivendo em situação de extrema pobreza. Segundo o IBGE, cerca de $58 \%$ dos brasileiros têm carências sociais, novo indicador de pobreza que leva em consideração a qualidade de vida (itens avaliados: acesso aos serviços básicos, atraso educacional, acesso à seguridade social e qualidade dos domicílios). Além disso, o índice de Gini, que mede a desigualdade na distribuição de renda entre os países e cujo coeficiente varia entre 0 e 1, foi de 0,490 em 2014, o que revela que o país ainda possui uma alta concentração de renda (IBGE, 2015).

A partir dos dois mandatos do presidente Fernando Henrique Cardoso, "o governo federal brasileiro passou a assumir o papel de formulador e indutor de políticas públicas voltadas para a concessão de crédito produtivo às populações de baixa renda" (Zouain \& Barone, 2007, p.370).

Mesmo com o ambiente favorável e de ser - Brasil o primeiro país a criar programas de microcrédito na América Latina - com a União Nordestina de Assistência a Pequenas Organizações (UNO) conduzida no Recife em 1973 (Feltrin, Ventura, \& Dodl, 2009), o setor de microfinanças no Brasil tem verificado um fraco ritmo de crescimento, com baixas taxas de penetração entre os empreendedores informais, trabalhadores por conta própria e microempreendedores, não obstante as políticas públicas implementadas pelo Estado a partir de 1990, com foco neste segmento (Santos \& Santos, 2017).

As operações de microcrédito são frequentemente consideradas pelo mercado financeiro como desvantajosas e caras em comparação às operações de crédito tradicionais, 
além das estatísticas de elevada mortalidade das micro e pequenas empresas (MPEs) (as quais fazem parte do público-alvo do microcrédito). Esses dois fatores reforçam o desinteresse da rede bancária em assumir os riscos dessas operações, limitando fortemente a expansão do segmento.

O que se observa como função mais recorrente do microcrédito praticado no Brasil é a concessão de capital de giro a pequenos negócios já estabelecidos. Em menor escala, aparecem as operações de crédito mistas, ou seja, parte para capital de giro e parte para investimento fixo (Cárdenas \& Oliveira, 2010). Segundo os autores, raramente o microcrédito é direcionado à formação de novos negócios.

Pereira, Mross, Lavorato e Aguiar (2009) explicam que os bancos comerciais no Brasil também não privilegiam empréstimos às instituições operadoras de microcrédito, principalmente às Organizações Sociais de Interesse Público (OSCIPs) em virtude da sua fragilidade patrimonial, bem como da dificuldade de mensuração adequada, pelos bancos, do risco envolvido nesse tipo de operação. Os autores ressaltam que as Sociedades de Crédito ao Microempreendedor (SCMs) e as OSCIPS, são proibidas, por lei, de obter recursos no mercado para garantir as suas operações de crédito. Dessa forma, os gestores das organizações de microcrédito também enfrentaram o desafio de equilibrar os objetivos sociais e financeiros e entender formas efetivas de avaliar a eficácia de sua organização (Armstrong et al., 2017).

A natureza distinta do contexto brasileiro em relação ao de outros países com conhecidas histórias de sucesso nas microfinanças, como Bangladesh, Bolívia e Indonésia (Ledgerwood, 1998), estimulou a realização dessa pesquisa, tendo como cenário a comunidade da Cidade de Deus, uma das maiores comunidades situadas no Estado do Rio de Janeiro. Além disso, como proposto por Santos e Santos (2017) e Gonzalez, Porto e Diniz (2017), é necessário o acompanhamento dos desdobramentos das iniciativas e orientações, advindas do governo federal, a respeito de microcrédito e microfinanças no Brasil, ao aprofundar o conhecimento sobre instituições específicas e de diferentes perfis.

No Rio de Janeiro, as favelas sempre apresentaram uma economia local própria caracterizada pelo mercado informal; contudo, com o processo de pacificação, o qual será descrito mais adiante neste trabalho, viu-se a possibilidade de fomento das estruturas econômicas por meio de oferta de microcrédito a trabalhadores informais, nano e microempreendedores por meio do projeto CDD - Cidade de Deus. Entretanto, há pouco conhecimento disponível sobre seu atendimento, de fato, no segmento da população excluído pelo mercado bancário tradicional ou se o projeto tem o seu foco voltado para a sustentabilidade das instituições, direcionando os recursos para outros segmentos não classificados como os mais pobres entre os pobres.

Assim, o presente estudo busca responder à seguinte questão de pesquisa: como o programa de microcrédito implementado na Cidade de Deus procurou atender ao segmento da população excluída pelo mercado bancário tradicional?

\section{MICROCRÉDITO: PRINCIPAIS CARACTE- RÍSTICAS}


Uma das primeiras definições no Brasil para a palavra microcrédito foi efetuada pelo Conselho da Comunidade Solidária, através da cartilha Introdução ao Microcrédito lançada em 2002, com a finalidade de difundir e incentivar a prática do microcrédito no país. Segundo Barone, Lima, Dantas \& Rezende (2002, p.11) microcrédito pode ser definido como:

A concessão de empréstimos de baixo valor a pequenos empreendedores informais e microempresas sem acesso formal ao sistema financeiro tradicional, principalmente por não terem como oferecer garantias reais. É um crédito destinado à produção (investimento e capital de giro) e é concedido com o uso de metodologia específica.

De acordo com Parente (2006, p.14), "o microcrédito carrega um conjunto de atributos referentes à forma como o crédito é concedido e restituído, à finalidade do empréstimo e ao público apto a figurar como tomador." O Quadro 1 sintetiza esses atributos.

Quadro 1. Características do microcrédito

\begin{tabular}{|l|l|}
\hline Características do microcrédito & Descrição \\
\hline Finalidade & $\begin{array}{l}\text { Trata-se de crédito produtivo. Financia capital } \\
\text { de giro e investimento fixo; não se destina a } \\
\text { financiar consumo. }\end{array}$ \\
\hline Público-alvo & $\begin{array}{l}\text { Pequenos empreendimentos informais, micro- } \\
\text { empresas e empresas de pequeno porte }\end{array}$ \\
\hline Montante & Baixo valor \\
\hline Múnência de garantias reais & $\begin{array}{l}\text { O empréstimo é geralmente realizado através } \\
\text { de fiador ou aval solidário }\end{array}$ \\
\hline Periodicidade de pagamentos & $\begin{array}{l}\text { Como grande parte dos empreendimentos } \\
\text { beneficiados são informais, a formalização é } \\
\text { limitada }\end{array}$ \\
\hline & $\begin{array}{l}\text { Pagamentos podem ser semanais ou até diá- } \\
\text { rios }\end{array}$ \\
\hline Orientação & $\begin{array}{l}\text { O crédito é realizado de forma assistida atra- } \\
\text { vés do agente de crédito }\end{array}$ \\
\hline
\end{tabular}

Fonte: adaptado de Barone et al. (2002) e Lhacer (2003) 
Dentre as características expostas no Quadro 1 e, de acordo com Marques, Santos, Siqueira e Santos (2011, p. 24), tem sido considerada "como um fator chave para o sucesso do microcrédito" a presença do agente de crédito, que promove o relacionamento e a intermediação entre a instituição e a comunidade. Segundo os autores, é o agente de crédito que faz as visitas aos potenciais clientes, divulga o serviço, orienta sobre os procedimentos e avalia os riscos de inadimplência, além de acompanhar o desenrolar das operações e a correta utilização do crédito pelos empreendedores. $O$ agente de crédito assume a tarefa de analisar e construir laços de relacionamento entre os potenciais clientes, desempenhando o papel de interlocutor da instituição do microcrédito.

A pesquisa de Armstrong et al. (2017) vai além e conclui que os agentes frequentemente assumem três perfis para que o microcrédito se desenvolva plenamente. Segundo os autores, os que "interagem" na construção de relações com os clientes e facilitam o fluxo de informações para os "conectores" e "institucionalizadores", que disseminam esses dados para os mercados, criam confiança e estimulam a circulação do crédito no setor de microfinanças. Além disso, os institucionalizadores estimulariam a inovação e as melhores práticas. Segundo Armstrong et al. (2017, p. 2):

As organizações das IMFs formam um ecossistema e co-criam valor, no qual as instituições de grande escala geram recursos e conscientização significativos para o movimento. Elas desempenham um papel importante e abrangente na manutenção da confiança no ecossistema, através de regras autogovernáveis [...] que canalizam recursos financeiros para as instituições regionais de pequena escala que trabalham diretamente com os mutuários e trazem uma profunda compreensão e experiência do cliente.

No Brasil, dois grandes blocos de instituições que atuam de forma complementar compõem a estrutura do setor de microfinanças. As instituições "de primeiro piso" atuam diretamente com o cliente final, fornecendo-lhe empréstimo e outros serviços complementares. Podem ser instituições do poder público, da iniciativa privada e da sociedade civil representadas pelas organizações não governamentais (ONGs), OSCIPS, cooperativas de crédito, sociedades de crédito ao microempreendedor e à empresa de pequeno porte (SCMs), fundos públicos e bancos comerciais públicos e privados .

As instituições "de segundo piso" propõem-se a atuar em prol da constituição de fundos no desenvolvimento institucional e na capacitação técnica das instituições de primeiro piso. São exemplos de instituições de segundo piso o BNDES e o SEBRAE.

É importante observar que os mais pobres entre os pobres têm sido excluídos dos serviços de microcrédito e que um dos principais motivos que dificultam o acesso desse público a essas linhas crédito é o elevado risco de inadimplência (Ali et al., 2017; Cuong, 2008; Duong \& Izumida, 2002; Lønborg \& Rasmussen, 2014; Loubere, 2016; Navajas et al., 2000). Também de acordo com Fafchamps et al. (2014), esse público mais carente pode acabar direcionando o dinheiro para suas necessidades diárias, ao invés de aplicar em investimentos produtivos para iniciar ou ex- 
pandir um negócio. Esses autores alegam que o retorno esperado para o crédito pode ser baixo devido à falta de capacitação dos microempreendedores e de conhecimento e educação financeira (Birochi \& Pozzebon, 2016). Estes aspectos somam-se a outros já apontados na literatura, como: "taxas de juros elevadas, cronograma de reembolso restritos, empréstimos insuficientes, falta de supervisão após o empréstimo e falta de educação e habilidades entre beneficiários do microcrédito" (Ali et al., 2017, p.13).

A primeira manifestação do microcrédito no Brasil ocorreu em 1973, antes das experiências de Yunus (Feltrin et al., 2009), como já mencionado. Entretanto, de acordo com dados do Banco Central do Brasil (BACEN), o microcrédito responde por apenas $0,4 \%$ do volume de operações e $0,2 \%$ do montante da carteira de crédito do Sistema Financeiro Nacional (BACEN, 2015). Esse cenário reforça algumas evidências de que, não obstante os esforços do marco regulatório e da multiplicidade de instituições envolvidas, os programas de microcrédito têm apresentado curiosamente uma evolução muito limitada em relação à demanda potencial.

Conforme proposto por Vasconcelos (2006), é necessário o acompanhamento dos desdobramentos das novas orientações a respeito de microcrédito e microfinanças no âmbito da gestão do governo federal. Nesse sentido, esta pesquisa pretende analisar em que extensão o programa de microcrédito implementado na Cidade de Deus vem atingindo o segmento da população excluído pelo mercado bancário tradicional. Para atingir esse objetivo, a seguir são analisadas duas perspectivas encontradas na literatura que têm norteado os debates a respeito do microcrédito.

Impactos de programas de microcrédito: duas abordagens

Alguns pesquisadores têm focado seus estudos na análise dos resultados das políticas públicas de microcrédito. A discussão a respeito dessa perspectiva fez surgir duas correntes de abordagem do problema definidas por Gulli (1998) como: poverty lending (crédito para os pobres) e financial syste$m s$ (sistemas financeiros). De acordo com a autora, poverty lending argumenta que a provisão de serviços financeiros é uma forma de combate à pobreza. Nesse sentido, espera-se que o microcrédito seja responsabilidade dos governos, das ONGS e dos doadores, visando ao atendimento dos clientes mais pobres. A segunda abordagem defende que as instituições de microfinanças (IMF's) devem focar na sua autossustentabilidade fazendo uso, para tanto, de taxas de juros maiores e baixos custos operacionais. Em um contexto de avanço do capitalismo financeiro em termos globais, o pensamento dominante na abordagem financial systems defende a geração de riqueza na base da pirâmide pela atuação de empresas privadas e desenvolvimento de mercados (Prahalad, 2006).

Autores como Harper (2001) e Prahalad (2006) defendem que os mais pobres são capazes de arcar com taxas de juros mais altas e serem bem-sucedidos, já que os menores empreendimentos apresentam maiores produtividades marginais de capital, ou seja, a produtividade do capital é muito alta quando ele é aplicado em microempresas que estavam sem recursos. 
Por outro lado, outros dois economistas têm se destacado por suas posições a respeito do capitalismo liberal e do combate à pobreza: Amartya Sen e Jeffrey Sachs (Hemais, Borelli, Casotti \& Dias, 2014), abrindo espaço para uma abordagem poverty lending.

Sen (2000), que foi agraciado com o prêmio o Prêmio Nobel de Economia em 1998, acredita que o indivíduo com pouca renda não possui as capacidades básicas do ser humano. Ele acredita que o potencial de uma pessoa ser mais produtiva e obter renda mais elevada aumenta à medida que ela alcança maiores capacidades para viver a vida. Nesse sentido, os serviços de saúde, educação básica, moradia, alimentação e, principalmente, justiça e igualdade social, contribuem para amenizar os problemas dos indivíduos de baixa renda.

Sachs (2005) também tem se dedicado, por mais de 20 anos, a compreender os resultados das políticas implementadas pelos países ricos na solução das consequências geradas pela carência de recursos, a partir de suas experiências em países como Bolívia, Polônia, Rússia, China, Índia e Quênia. No Brasil, essa discussão é circunscrita aos argumentos das correntes desenvolvimentista e minimalista (Soares \& Sobrinho, 2008). As IMF's minimalistas focam mais na sustentabilidade das instituições. De acordo com Gonzalez-Vega (2000), a corrente minimalista preocupa-se mais com os aspectos técnicos das microfinanças em detrimento da abrangência dos impactos sociais do microcrédito.

Já as instituições desenvolvimentistas costumam oferecer, além do crédito, serviços não-financeiros como qualificação, asses- soria na gestão dos negócios e até distribuição de alimentos. Entretanto, os custos incorridos na oferta de tais serviços podem prejudicar a sustentabilidade da instituição.

Assim, o microcrédito tem relevância estratégica. Dado seu caráter concreto, a inclusão do microempreendedor no sistema financeiro - ainda que em volumes muito pequenos, constitui uma mudança qualitativa. A inclusão tende a fazê-lo demandar, gradualmente, o acesso a serviços não financeiros, estabelecendo uma ponte para resolver outras questões afetas à falta de oportunidades e de superação da própria situação de desigualdade (Parente, 2006). Nessa abordagem, destacam-se a seguir a economia solidária e os bancos comunitários como instrumentos que podem ser utilizadas para a inserção econômica e social.

Economia solidária: a experiência dos bancos comunitários de desenvolvimento

Economia solidária é definida como:

O conjunto de atividades econômicas - de produção, distribuição, consumo, poupança e crédito - organizadas sob a forma de autogestão compreende uma variedade de práticas econômicas e sociais organizadas sob a forma de cooperativas, associações, clubes de troca, empresas autogestionárias, redes de cooperação, entre outras, que realizam atividades de produção de bens, prestação de serviços, finanças solidárias, trocas, comércio justo e consumo solidário. (Ministério do Trabalho e Emprego, 2015, p. 6)

Dentre os vários exemplos de experiências de empreendimentos de economia solidária, 
como associações de moradores, cooperativas populares e grupos produtivos, destacam-se os Bancos Comunitários de Desenvolvimento (BCD), que constituem o campo das chamadas finanças solidárias ou finanças de proximidade (Parente, 2006).

O conceito de BCD, está relacionado ao desenvolvimento da economia local. Além do microcrédito produtivo e para consumo, o banco comunitário busca "aquecer" a economia local através de clubes de trocas, feiras, balcão de empregos, moeda social, etc. As características básicas de um banco comunitário, de acordo com a Rede Brasileira de Bancos Comunitários (2006), são:

1) Atua em comunidades com alto grau de exclusão e desigualdade;

2) Fomenta a comercialização dos empreendimentos locais, articulando produtores e consumidores em rede;

3) Atua com linhas de crédito em moeda nacional e em moeda social circulante local;

4) Promove o desenvolvimento local através do financiamento à produção e ao consumo local;

5) É criado e gerido pela própria comunidade;

6) Seu público se caracteriza pelo alto grau de vulnerabilidade social;

7) Sua sustentabilidade, em médio prazo, deve ser subsidiada.

Nesse sentido, o banco comunitário baseia-se no tripé: gestão comunitária, sistema integrado de desenvolvimento e moeda social circulante local (Passos, 2007).

Segundo Vieira (2011), embora durante muito tempo tenha sido proibida qualquer moe- da paralela em território brasileiro, o Banco Central do Brasil passou a autorizar a circulação desse tipo de moeda nestes casos especiais, já que os bancos comunitários só podem funcionar ante a aprovação do governo. Para o autor, essas instituições possuem características particulares, pois não buscam o lucro - como todas as instituições financeiras tradicionais. Elas oferecem empréstimos com juros bem mais baixos ou, em alguns casos, sem juros (principalmente se o empréstimo for em moeda social), já que esta só tem valor na área predeterminada. No entanto, o objetivo fundamental é fortalecer o comércio e a comunidade onde se localizam. Vale destacar que os BCDs não têm personalidade jurídica própria e são, em geral, ancorados juridicamente por associações locais que assumem ora a forma de associações de bairro, ora de organizações não-governamentais ou OSCIP (Rigo, 2014).

Percebe-se pelo exposto que os programas de microcrédito ofertados por diferentes instituições podem adotar instrumentos capazes de ter impacto na diminuição da pobreza no segmento da população excluída pelo mercado bancário tradicional. Resta, portanto, analisar como o programa de microcrédito implementado na Cidade de Deus procurou atender ao segmento da população excluído pelo mercado bancário tradicional.

\section{METODOLOGIA}

A presente pesquisa consiste em um estudo de caso, por meio de pesquisa de campo, na comunidade da Cidade de Deus, que buscou analisar como se dá o atendimento da população tradicionalmente excluída do setor bancário. A coleta de dados ocorreu no 
período entre novembro de 2013 a maio de 2015.

A escolha pela realização do estudo de campo naquela comunidade pautou-se no ambiente propício criado com a instalação de instituições financeiras e de um banco comunitário na localidade, após o período de pacificação, no ano de 2009. Nessa fase também ocorreu a criação de uma moeda local, denominada CDD, reunindo, desta for$\mathrm{ma}$, elementos importantes para o desenvolvimento de uma pesquisa sobre o tema proposto.

Em uma primeira etapa, foram realizadas três visitas exploratórias na comunidade, em dezembro de 2013, para conhecer o ambiente e identificar os principais atores que pode- riam contribuir com informações e opiniões a respeito da utilização de linhas de crédito voltadas para a população de baixa renda e os possíveis benefícios gerados para seus tomadores. Com base nas informações levantadas, foi efetuada nova coleta de dados nos 17 meses subsequentes, por meio de entrevistas individuais em profundidade com duração de aproximadamente 60 minutos, conduzidas por meio de um roteiro semiestruturado.

Foram realizadas 28 entrevistas, das quais 7 com representantes de agências e instituições que atuam no desenvolvimento e na promoção de programas sociais no Rio de Janeiro e 21 com empreendedores da comunidade. 
Quadro 2. Sujeitos participantes da pesquisa

\begin{tabular}{|c|c|c|}
\hline Órgão & Propósito do organismo & Entrevistado \\
\hline $\begin{array}{c}\text { Subsecretaria de Integração dos } \\
\text { Programas Sociais da Secretaria Es- } \\
\text { tadual de Assistência Social e Direitos } \\
\text { Humanos }\end{array}$ & $\begin{array}{l}\text { Implantar e acompanhar o desenvolvimento } \\
\text { de programas sociais no Estado do Rio de } \\
\text { Janeiro }\end{array}$ & subsecretário \\
\hline $\begin{array}{l}\text { Secretaria Especial de Desenvolvi- } \\
\text { mento de Economia Solidária }\end{array}$ & $\begin{array}{l}\text { Desenvolver projetos de economia solidária } \\
\text { no Estado do Rio de Janeiro }\end{array}$ & $\begin{array}{l}\text { diretora de Economia } \\
\text { solidária e comércio } \\
\text { justo }\end{array}$ \\
\hline $\begin{array}{c}\text { Banco Comunitário da Cidade de } \\
\text { Deus }\end{array}$ & $\begin{array}{l}\text { Fornecer crédito de pequenos valores a mi- } \\
\text { croempreendores informais em moeda local }\end{array}$ & presidente \\
\hline Instituto Pereira Passos & $\begin{array}{c}\text { Implantar e acompanhar o programa } \\
\text { Rio+Social nas comunidades pacificadas do } \\
\text { Rio de Janeiro. }\end{array}$ & $\begin{array}{l}\text { responsável pelo } \\
\text { programa na CDD }\end{array}$ \\
\hline $\begin{array}{c}\text { Banco do Brasil - Ag. Cidade de } \\
\text { Deus }\end{array}$ & $\begin{array}{l}\text { Fornecer crédito a microempreendedores } \\
\text { formais, microempresas. Fomentar a eco- } \\
\text { nomia local. }\end{array}$ & gerente de agência \\
\hline SEBRAE & $\begin{array}{l}\text { Orientar quanto à adequada utilização do } \\
\text { crédito, capacitar microempreendedores em } \\
\text { relação ao seu negócio. }\end{array}$ & $\begin{array}{l}\text { responsável pelo pro- } \\
\text { grama microcrédito na } \\
\text { CDD }\end{array}$ \\
\hline AGERIO & $\begin{array}{l}\text { Fomentar a economia local através do mi- } \\
\text { crocrédito }\end{array}$ & $\begin{array}{l}\text { representante da Age- } \\
\text { Rio }\end{array}$ \\
\hline Agente de crédito da AGERIO & $\begin{array}{l}\text { Elemento de ligação entre a instituição de } \\
\text { crédito e os empreendedores }\end{array}$ & agente de crédito \\
\hline Microempreendedores locais & $\begin{array}{l}\text { Realizar localmente atividade econômica } \\
\text { relacionada à produção e comercialização } \\
\text { de bens e serviços }\end{array}$ & $\begin{array}{l}\text { 21empreendedores } \\
\text { formais e informais } \\
\text { atuantes na CDD }\end{array}$ \\
\hline
\end{tabular}

A seleção dos empreendedores ocorreu de forma aleatória, com o intuito de evitar o viés de seleção. Os dados extraídos das entrevistas representam uma pequena amostra do perfil dos empreendedores estabelecidos na localidade, tendo sido utilizadas informações individuais e do empreendimento como variáveis de análise. 
Vera Lúcia de Aguiar Kelly - Ana Carolina Pimentel Duarte da Fonseca - Fernanda Filgueiras Sauerbronn

Quadro 3. Perfil dos empreendedores entrevistados pela pesquisa

\begin{tabular}{|c|c|c|c|c|c|c|}
\hline entrevistado & $\begin{array}{l}\text { Setor de } \\
\text { atividade }\end{array}$ & Sexo & Idade & Escolaridade & Naturalidade & $\begin{array}{l}\text { Microempreendedor } \\
\text { individual (MEI) }\end{array}$ \\
\hline no. 1 & comércio & $F$ & 52 & $1^{\circ}$. grau & Paraíba & Sim \\
\hline no. 2 & comércio & $M$ & 68 & $1^{\circ}$. grau & Paraíba & Sim \\
\hline no. 3 & serviço & $F$ & 39 & $1^{\circ} \cdot$ grau & Minas Gerais & Sim \\
\hline no. 4 & comércio & $F$ & 38 & $2^{\circ}$.grau & Pernambuco & Não \\
\hline no. 5 & comércio & $\mathrm{F}$ & 29 & $2^{\circ} . \mathrm{grau}$ & Ceará & Sim \\
\hline no. 6 & comércio & $\mathrm{F}$ & 24 & $2^{\circ} \cdot$ grau & Rio de Janeiro & Sim \\
\hline no. 7 & serviço & $F$ & 43 & $1^{\circ}$. grau & Rio de Janeiro & Sim \\
\hline no. 8 & comércio & $\mathrm{F}$ & 28 & $2^{\circ}$.grau incompleto & Rio de Janeiro & Não \\
\hline no. 9 & comércio & $F$ & 54 & $2^{\circ}$.grau & Rio de Janeiro & Sim \\
\hline no. 10 & comércio & $\mathrm{F}$ & 62 & $2^{\circ}$. grau & Rio de Janeiro & Sim \\
\hline no. 11 & comércio & $F$ & 53 & $2^{\circ}$.grau & Rio de Janeiro & Sim \\
\hline no. 12 & serviço & $F$ & 54 & $1^{\circ} \cdot$ grau & Rio de Janeiro & Sim \\
\hline n. ${ }^{\circ} .13$ & serviço & $\mathrm{F}$ & 34 & $2^{\circ} \cdot$ grau & Rio de Janeiro & Sim \\
\hline $\mathrm{n}^{\circ} .14$ & comércio & $\mathrm{M}$ & 38 & 2o. grau & Rio de Janeiro & Sim \\
\hline $\mathrm{n}^{\circ} .15$ & comércio & $\mathrm{M}$ & 30 & 2o. grau & Rio de Janeiro & Sim \\
\hline $\mathrm{n}^{\circ} .16$ & comércio & $\mathrm{M}$ & 65 & $2^{\circ} \cdot$ grau & Rio de Janeiro & Sim \\
\hline $\mathrm{n}^{\circ} .17$ & serviço & M & 37 & $1^{\circ}$. grau incompleto & Rio de Janeiro & Não \\
\hline $\mathrm{n}^{\circ} .18$ & comércio & $M$ & 46 & $1^{\circ}$. grau incompleto & Rio de Janeiro & Sim \\
\hline $\mathrm{n}^{0} .19$ & serviço & $\mathrm{M}$ & 26 & $2^{\circ}$. grau & Rio de Janeiro & Sim \\
\hline$n^{\circ} .20$ & comércio & $M$ & 31 & $2^{\circ}$. grau & Rio de Janeiro & Não \\
\hline$n^{0} .21$ & serviço & $F$ & 25 & $3^{\circ}$. grau & Rio de Janeiro & Sim \\
\hline
\end{tabular}

Dentre as informações individuais coletadas estão: gênero, idade, grau de instrução, Estado de origem e ramo de atividade. As informações coletadas sobre o empreendimento foram: tempo de atividade da firma, tipo de organização, quantidade de empregados e tipo de crédito utilizado na implantação/expansão do negócio.

\section{ANÁLISE E DISCUSSÃO DOS RESULTA- DOS}

A análise dos resultados foi organizada em cinco blocos. O primeiro refere-se ao contexto da comunidade após o processo de pacificação e seus reflexos sobre as ações de microcrédito. $O$ segundo refere-se às características do microcrédito na comunidade, abrangendo o perfil dos tomadores de microcrédito, enquanto o terceiro descreve as dificuldades no crescimento do microcrédito na região. Finalmente, os dois últimos blocos discutem o papel social do microcrédito e o atendimento à população de extrema pobreza.

Nesse sentido, buscou-se analisar a atuação das instituições financeiras e do banco comunitário com base nas abordagens poverty lending (ou desenvolvimentista) e financial systems (ou minimalista) apontadas na revisão de literatura. Destaca-se que os 
resultados obtidos têm o objetivo de produzir reflexões que contribuam para o avanço dos programas de microcrédito implementados, bem como produzir conhecimentos locais que permitam uma compreensão mais aprofundada sobre como o programa de microcrédito implementado na Cidade de Deus procurou atender ao segmento da população excluído pelo mercado bancário tradicional.

Pacificação, acessos a serviços e microcrédito

Os entrevistados relataram ter havido meIhora considerável nas condições de vida na localidade após o processo de pacificação com a instalação da UPP. A partir de 2009, houve a diminuição da criminalidade e acesso a serviços tais como: energia elétrica de melhor qualidade, iluminação pública, esgoto, recolhimento de lixo, internet e telefonia fixa. As empresas responsáveis por serviços de infraestrutura (por exemplo, Light, Comlurb e Ol) passaram a ter acesso à comunidade, bem como empresas de TV por assinatura (por exemplo, SKY e Claro) e grandes empresas varejistas (como Casas Bahia e Ponto Frio).

Outro benefício gerado pela pacificação foi a instalação de agências bancárias na comunidade. O primeiro a "entrar" na Cidade de Deus foi o Banco do Brasil, em janeiro de 2011, dois anos após a implantação da UPP. Segundo informações do funcionário do banco, a instituição buscou inspiração em Yunus e no projeto desenvolvido pelo Banco do Nordeste do Brasil. O foco seria atuar entre os microempreendedores -- formais e informais -- e pequenos produtores, em parceria com as associações locais.

\begin{abstract}
Existe um grande número de associações aqui. Selecionamos sete delas que tinham representatividade junto à comunidade. Também buscamos parceria com a UPP Social para entender a cultura empresarial local [...] o SEBRAE também foi fundamental no processo de conscientização dos empreendedores quanto à utilização adequada do crédito. (gerente do Banco do Brasil, agência Cidade de Deus)
\end{abstract}

Também após a pacificação, segundo relatos de entrevistas, outros bancos e instituições de fomento passaram a atuar na comunidade e apontam a influência de outras políticas públicas (no caso segurança pública) para o desenvolvimento das políticas de microcrédito. Passaram a atuar na comunidade a Caixa Econômica Federal (Caixa), Bradesco, Vivacred. Houve ainda oferta de linhas de financiamento do BNDES. As organizações que passaram a ofertar microcrédito na comunidade procuraram aproximar-se da realidade local, conforme relato:

A agência trabalha com capacitores de negócios. Recrutamos as pessoas da própria comunidade, que trabalham in loco, realizando visitas aos estabelecimentos. Assim, contamos com o conhecimento e o relacionamento desses agentes com os moradores, facilitando nosso trabalho na obtenção de informações sobre os tomadores. Também temos unidades móveis que visitam as comunidades pacificadas semanalmente, orientando os microempreendedores. (representante da AgeRio)

Entretanto, o Banco do Brasil não possuía agentes de crédito atuando diretamente na comunidade, sendo necessário que o toma- 
Vera Lúcia de Aguiar Kelly - Ana Carolina Pimentel Duarte da Fonseca - Fernanda Filgueiras Sauerbronn

dor se dirigisse ao estabelecimento bancário e formalizasse sua intenção através da confecção de cadastro.

Inspirado na iniciativa de sucesso do Banco Palmas, o Banco Comunitário da Cidade de Deus (BCCD) foi inaugurado, em setembro de 2011, com o objetivo de incentivar os moradores a produzirem e consumirem produtos e serviços dentro da própria comunidade, pois assim, conforme citou a presidente da Agência de Desenvolvimento Local e diretora do BCCD, "a riqueza não sai do território".

Melo Neto, fundador do primeiro banco comunitário no Brasil e diretor do Instituto Banco Palmas, esteve na comunidade durante três meses, acompanhando a instalação do BCCD, bem como treinando as equipes que iam gerenciar e atuar como agentes de crédito. Ao todo, o conselho administrativo da instituição era formado por 20 pessoas, todas da comunidade. Concomitantemente à abertura do banco comunitário, foi autorizada pelo BACEN a circulação da moeda local chamada de CDD. Os valores das cédulas variavam de 0,50 a 10,00. A paridade da moeda era de 1 para $1(1 \mathrm{CDD}=\mathrm{R} \$ 1,00)$.

No início tivemos muita dificuldade para convencer os moradores a trocarem seus reais por CDD e também os comerciantes a aceitarem a nova moeda, mas contamos com a ajuda da Secretaria Nacional de Economia Solidária, que juntamente com a Prefeitura do Rio contrataram a consultoria do Instituto Palmas para nos ajudar" [...] (presidente do Banco Comunitário Cidade de Deus).

Esse relato indica que a implementação do microcrédito na comunidade foi também influenciada pelo perfil dos usuários, podendo trazer contornos e características específicas ao caso.

Características do microcrédito na comunidade

As características do microcrédito na comunidade podem inicialmente ser compreendidas em função do perfil de seus usuários. A maior parte dos microempreendedores entrevistados concentra-se na faixa etária da população economicamente ativa. Verificou-se que $75 \%$ desses empreendedores trabalhavam em regime de carteira assinada antes de ter o próprio negócio. Como não conseguiram a reinserção no mercado de trabalho formal, a iniciativa empreendedora foi a solução encontrada para prover o próprio sustento e de sua família (empreendedorismo por necessidade). Observa-se também uma participação maior da mulher como chefe de família e provedora, confirmando os achados de Worthen (2012), de que a maioria dos receptores de microcrédito em todo o mundo são muIheres de baixa renda. Dentre os dados da pesquisa, destaca-se ainda a concentração de pequenos negócios no segmento de comércio $(63 \%)$ e serviços $(26 \%)$.

Outra importante característica dos usuários deve-se ao fato de que os microempreendores parecem possuir um nível baixo de educação financeira, conforme relatos:

Sou morador da Cidade de Deus. Fui criado na comunidade e aqui as pessoas não se preocupam em ter o nome "limpo". Muitos ficam surpresos quando são informados que possuem restrições no SERASA e SPC. De dez propostas da Cidade de Deus, apenas 
duas passam. (agente de crédito)

Em todas as comunidades pacificadas -- já foram feitos mais de 62 mil atendimentos desde 2011 -- o perfil dos empreendedores é muito parecido: não fazem planejamento (quando fazem é de curto prazo); não se veem como empresários; não fazem o controle financeiro; não separam as finanças pessoais das finanças da empresa; utilizam recursos próprios. (representante do SEBRAE)
A carência na educação financeira e no cuidado com as finanças pessoais vem alimentando um ciclo vicioso. Esse círculo indica que as ações de microcrédito podem ser compreendidas equivocamente como "maior renda" destinada a maior consumo e ao saneamento de endividamentos de consumo ao invés de atividades produtivas, confirmando a interpretação do estudo de Hulme et al. (2007).

Figura 1. Círculo vicioso

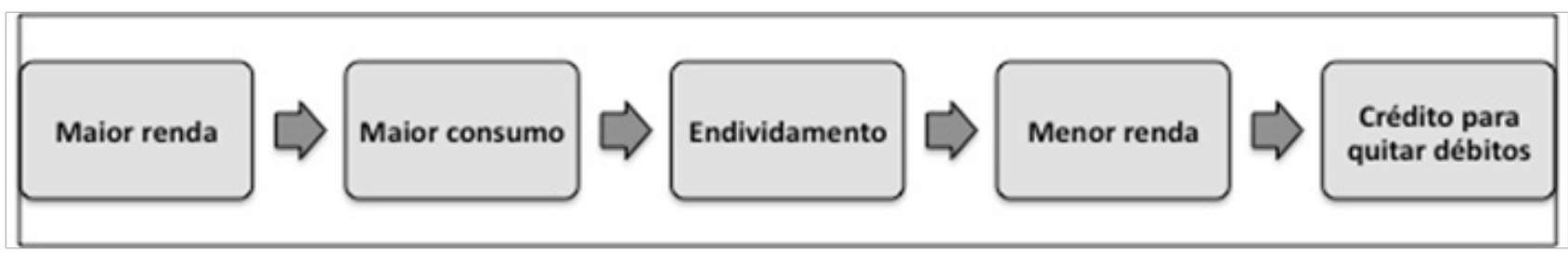

Sendo a educação financeira um tema relevante para a concessão de crédito em geral, e mais especificamente em ações de microfinanças, percebe-se que o potencial de desenvolvimento social na comunidade não foi plenamente alcançado com uma mudança na cultura de acesso e uso de recursos financeiros. Essa discussão remete à limitação do potencial de desenvolvimento no nível individual e o consequente desafio de sustentabilidade de um programa de microcrédito voltado ao lado social, como foi abordado pelos defensores da corrente minimalista (Ledgerwood, 1998).

\section{Dificuldades no crescimento do microcrédi- to na região}

Ao analisar as percepções dos atores envolvidos neste estudo, foi possível identificar vários entraves, em termos econômicos, ao crescimento das ações de microfinanças. Evidencia-se maior preocupação com a regulação do setor e com os limites operacionais, em alinhamento ao estudo de Liñares-Zegarra e Wilson (2017), do que com os resultados de cunho social a serem alcançados pelo microcrédito, em alinhamento às críticas de Ali et al. (2017). No caso do CDD, a valorização da perspectiva minimalista frente à perspectiva desenvolvimentista ficou muito clara na fala dos representantes das instituições financeiras entrevistadas. No caso da AgeRio e do Banco do Brasil, tal fato pode ser observado pela preocupação com o crescimento da carteira de crédito e com os índices de inadimplência (pontos destacados durante as entrevistas).

Faço a divulgação da linha de crédito através de folders (panfletagem) e também visitando os estabelecimentos comerciais: 
Vera Lúcia de Aguiar Kelly - Ana Carolina Pimentel Duarte da Fonseca - Fernanda Filgueiras Sauerbronn

desde o vendedor de cachorro quente até o dono de farmácia, da padaria, o borracheiro da esquina... A maioria dos clientes são indicados pelo SEBRAE ou pelos próprios clientes já tomadores de crédito. (agente de crédito)

[...] houve um aumento nas taxas de juros e os valores ofertados aos empreendedores que nos procuram pela primeira vez são muito baixos, assim como o prazo para pagamento, tornando-se inviável para o tomador. Mas para aqueles que já são clientes (com bom histórico), as condições negociais vão melhorando gradativamente, como a disponibilização de valores mais elevados e a dispensa de garantia pessoal. (representante do Banco do Brasil)

Nesse fragmento de entrevista, discute-se a ideia de continuidade do crédito ligada à capacidade de pagamento do empreendedor (viés econômico), sem levar em conta a disponibilização do crédito às camadas mais pobres e excluídas do segmento bancário tradicional (Gulli,1998). Este aspecto corrobora o viés econômico, conforme apontado por Liñares-Zegarra e Wilson (2017), no qual os níveis de empréstimos ruins acabam por direcionar a capacidade de oferta e, consequentemente, orientar o crescimento da instituição.

Outros fatores identificados como fortes entraves ao desenvolvimento das microfinanças são as dificuldades de acesso às fontes de recursos pelas instituições operadoras de microcrédito (OSCIPs, Sociedades de Crédito aos Microempreendedores (SCM's), cooperativas de crédito e bancos comunitários) e as restritas relações institucionais entre governo, doadores de recursos, instituições operadoras de microcrédito e demais stakeholders, que não favorecem a integração de ações coordenadas para continuidade das práticas de políticas públicas e dificultam o diálogo com a sociedade. Estes achados corroboram a importância das relações entre as instituições, conforme indicado no estudo de Armstrong et al. (2017) sobre a cocriação de valor por IMF's.

No caso da CCD, os dados da presente pesquisa confirmam os achados de Rigo (2014) sobre a dificuldade de acesso a recursos por bancos comunitários. A autora apontou que os principais desafios enfrentados pelos bancos comunitários estavam intimamente relacionados com a insuficiência de recursos para formação do lastro.

O depoimento da representante da Secretaria Especial de Economia Solidária (SEDES) Rio, ratifica, durante a sua entrevista, os pontos aqui destacados com relação ao desempenho do BCD. Segundo ela, esse foi o primeiro $B C D$ inaugurado no município do Rio de Janeiro, fruto do projeto Rio Ecosol. Entretanto, mesmo com o apoio da Secretaria Nacional de Economia Solidária (SENAES) e das parcerias do Instituto Palmas, USP e Caixa Econômica Federal, ocorreram algumas falhas na implantação e no acompanhamento das atividades exercidas pelo banco comunitário. A representante da SEDES destacou, como exemplos, o baixo volume de recursos destinados pelo SENAES para lastrear a carteira de crédito do banco e $o$ alto índice de rotatividade entre os membros da Agência de Desenvolvimento Local, responsável pela gestão do BCCC. 
A ausência de lastro, consequentemente, compromete as operações de crédito, bem como restringe as possibilidades de emissão da moeda social pelo BCCD, uma vez que os bancos comunitários necessitam ter em caixa, em reais, o mesmo montante de moeda local em circulação nas comunidades, com vistas a facilitar a troca de moedas pelos usuários.

O BCCD dependia, quase que exclusivamente, de fontes doadoras de recursos e, após o assalto sofrido no início de 2014, o banco não teve mais acesso aos recursos que eram repassados pela Caixa, contribuindo para a descontinuidade de suas atividades.

Depois do assalto sofrido no início de 2014, a moeda social praticamente parou de circular e o banco comunitário não possui recursos para arcar com suas despesas operacionais, estando com suas atividades suspensas. (presidente do Banco Comunitário CDD)

De acordo com informações da presidente responsável pela gestão do banco comunitário, os recursos do BNDES e do Banco do Brasil, que supostamente teriam sido liberados para constituição de um fundo de crédito do BCCD, até a data em que foram realizadas as entrevistas, não haviam "entrado" na conta. Alternativas estavam sendo avaliadas pelos gestores, conforme relato:

Atualmente estamos rediscutindo o projeto do banco comunitário com os representantes da Agência de Desenvolvimento Comunitário e da comunidade. Acreditamos que a implantação do cartão de crédito social, como o que existe no Conjunto
Palmeira-CE, contribuirá para movimentar a economia na Cidade de Deus (diretora da SEDES).

Tendo apontado as dificuldades do desenvolvimento do microcrédito na região, torna-se necessário analisar o papel social deste e a capacidade de atendimento da população de extrema pobreza.

\section{Papel social do microcrédito}

Considerando a proposta deste estudo de analisar como o programa de microcrédito procurou atender ao segmento da população excluído pelo mercado bancário tradicional, observa-se que as experiências de microcrédito na Cidade de Deus têm um aspecto muito mais complementar ao mercado financeiro do que gerador de ações que busquem atender às necessidades dos mais pobres. Como já mencionado, em entrevista, o funcionário do Banco do Brasil esclarece que as condições atuais da linha de microcrédito ofertada pelo banco não favorecem os tomadores sem experiência de crédito com a instituição.

Outro aspecto observado é um dos pilares dentre os difundidos por Yunus e que norteava a ideia de crédito para comunidades pobres: o aval solidário (Miranda, 2011).

É necessário que o empreendedor tenha pelo menos seis meses de exercício da atividade, não possuir restrições e apresentar fiador com renda comprovada. Também serve o aval de dois ou mais empreendedores, que dividirão com o tomador 0 risco do negócio. (agente de crédito)

Mesmo com as informações do agente de 
crédito quanto à possibilidade de utilização do aval solidário, na prática a concessão de crédito ocorre de maneira individual. $\mathrm{O}$ uso do aval solidário não é estimulado pelas instituições financeiras em virtude do custo e do risco envolvidos. Durante as entrevistas, tanto o representante do Banco do Brasil quanto o da AgeRio evidenciaram a exigência de fiador, com renda comprovada e ausência de restrições cadastrais como condicionantes para ter acesso aos recursos do microcrédito.

Os valores emprestados variam, em média, em torno de $\mathrm{R} \$ 4.500,00$ e são exigidas garantias pessoais (fiadores com renda comprovada). (representante da AgeRio)

Com referência à utilização de recursos do microcrédito, apenas $20 \%$ dos entrevistados fizeram uso desse recurso no empreendimento; $75 \%$ optou por utilizar recursos próprios ou empréstimos de familiares e amigos; e $5 \%$ fizeram uso do crédito direto ao consumidor (CDC). Alguns pontos levantados pelos entrevistados podem justificar a baixa utilização do microcrédito pelos microempreendedores, como: existência de restrições cadastrais, desconhecimento sobre as linhas de microcrédito, altas taxas de juros cobradas pelas instituições financeiras e exigência de garantias pessoais (avalista com renda comprovada).

Eu não consegui pegar o empréstimo porque não consegui arrumar avalista. Então eu peguei com uns chineses que fazem empréstimo aqui na comunidade. Só que eles só fazem para quem é indicado por um cliente deles. Peguei $R \$ 500,00$ para pagar o mês que vem. Não me exigiram fiador nem nada. Todo mundo aqui faz isso[...] (empreendedor $n$ ‥ 3)

Quem não tem nada, não tem como pegar empréstimo, se não tem bens vai declarar o quê? Só honestidade e boa vontade não ajudam (empreendedor no. 2)

Aliada a essas exigências, a liberação de pequenos valores e prazos curtos de pagamento dos empréstimos tem afastado os microempreendedores do microcrédito, que têm preferido utilizar outras fontes de recursos já mencionadas para impulsionar os seus negócios ou mesmo pagar dívidas, confundindo muitas vezes o microcrédito produtivo com o microcrédito para consumo.

Adicionalmente, durante o período em que ocorreu o estudo de campo, foi possível identificar que a moeda social CDD pouco contribuiu para o desenvolvimento do comércio da comunidade e do cumprimento do papel social do microcrédito. $O$ projeto foi difundido entre os comerciantes com o envolvimento da associação de comerciantes local no processo de divulgação da moeda CDD. Entretanto, pode-se dizer que o processo de divulgação não ocorreu plenamente com os demais moradores da comunidade, que viam a CDD com ceticismo, talvez por não terem compreendido seu real significado e os efeitos de sua adoção no desenvolvimento local.

A dinâmica de circulação da moeda CDD não foi bem internalizada pelos moradores, bem como pelos comerciantes locais, o que dificultou a ampla aceitação da moeda pela comunidade (diretora da SEDES).

Também há de se considerar que o curto período de existência do BCCD contribuiu para 
o fracasso do projeto, já que era o principal fomentador da CDD na comunidade, minimizando assim o papel social do microcrédito na região.

O atendimento à população de extrema pobreza

O BCCD tinha como principal foco atender aos setores mais vulneráveis da população pobre (extrema pobreza) da comunidade, promovendo a inclusão social, um dos pilares fundamentais de sua ação. Por esse motivo, procurou-se observar durante a realização do estudo de campo a inserção do microcrédito nas áreas de extrema pobreza da comunidade. Durante a realização do estudo de campo foi possível perceber que a população em situação de extrema pobreza na comunidade não vem sendo atendida pelos programas de microcrédito. Ainda existem áreas em que se encontram pessoas vivendo em situação de pobreza extrema, privadas de todos aqueles aspectos mencionados por Sen (2000) como necessários para o ser humano ter uma vida digna.

Por questões de segurança, não foi possível ter acesso a esse grupo de moradores, uma vez que residem em local de difícil acesso e de risco. Segundo informações obtidas com policiais da UPP local, a região, denominada Caratê, onde se localizam os novos conjuntos habitacionais, não deveria ser visitada por ser uma área onde "ainda imperava" a ação de traficantes. Alguns microempreendedores entrevistados declararam:

A gente arrecada mantimentos com os comerciantes da comunidade. Fazemos as cestas básicas e levamos lá. Todo mês a gente faz isso. Mas eu tenho medo de ir lá. Da última vez, teve tiroteio. (empreendedora ํ․ . 7)

É muita miséria. Dá vontade de chorar. Quando recebem as cestas básicas é uma alegria danada. (empreendedora ํㅡ. 6).

Ainda reforçando a percepção de que esta parcela de potencial público do microcrédito na comunidade não vem sendo atendida, destaca-se a observação efetuada pelo agente de crédito. No depoimento apresentado anteriormente, ele esclarece que procura atender aos proponentes que já têm um negócio com possibilidade de crescimento e com boas referências, em detrimento daqueles que estão iniciando o seu negócio. Adicionalmente, a instituição que tinha o seu foco voltado para as pessoas mais carentes - o BCCD -- não chegou a atingir seu objetivo, em função dos problemas já mencionados anteriormente e do curto período de existência.

\section{CONSIDERAÇÕES FINAIS}

O presente estudo buscou analisar como o programa de microcrédito implementado na Cidade de Deus procurou atender ao segmento da população excluído pelo mercado bancário tradicional, à luz de duas abordagens ao microcrédito (poverty lending e financial systems) e levando-se em consideração os aspectos social e econômico que permeiam a realidade local.

Os resultados apontam que os moradores da Cidade de Deus convivem com a escassez de recursos físicos, humanos e financeiros, assim como com a escassez de serviços e políticas públicas. Nesse sentido, o ambiente analisado constitui-se num interessante 
campo para futuras investigações sobre as carências que devem ser combatidas por meio de políticas públicas, em particular aquelas afetas ao microcrédito. Sob esse prisma, foi a partir do processo de pacificação da comunidade que os microempreendendores formais e informais começaram a ter acesso ao microcrédito, com a instalação de instituições financeiras e criação do banco comunitário na localidade.

Por sua vez, a instalação do banco comunitário veio ao encontro dos anseios de um outro tipo de público do microcrédito: o trabalhador informal, que dificilmente obteria crédito através de um banco comercial tradicional, dada a ausência de comprovação de renda, como é o caso dos artesãos, costureiras, ambulantes de uma maneira geral, etc. As várias experiências ocorridas em países como Índia (Guérin \& Kumar, 2017), Bangladesh (Ali et al., 2017), China (Loubere, 2016), Bolívia (Navajas et al., 2000), Nicarágua (Mason, 2014) e México (Worthen, 2012), dentre outros, foram capazes de permitir a inclusão social e a geração de trabaIho e renda para os mais pobres, assumindo uma importância crescente como política pública de desenvolvimento. No entanto, no Brasil as estratégias para o segmento microfinanceiro seguem a lógica do sistema financeiro, afastando-se das políticas sociais.

Os resultados deste estudo sugerem que a concessão de crédito aos mais pobres não tem sido prioridade das instituições financeiras em geral, devido aos elevados custos operacionais, aos reduzidos valores de empréstimos, à assimetria de informações e à elevada relação custo-benefício.

Assim, no que se refere às instituições fi- nanceiras entrevistadas, Banco do Brasil e AgeRio, parece ocorrer uma certa seletividade dos proponentes ao crédito. Ambas as instituições dão prioridade à concessão do crédito àqueles que possuem experiência em seu negócio, ou seja, os microempreendedores formais e informais já estabelecidos, em detrimento daqueles que não possuem nenhuma vivência negocial, mas apenas a "vontade de mudar de vida".

Por outro lado, o Banco Comunitário da Cidade de Deus -- cujo foco era atender às camadas mais pobres da comunidade -- apresentava sérios problemas de gestão, crises internas, dificuldades na obtenção de fundos e subsídios para a manutenção de suas operações pouco rentáveis e acabou sucumbindo diante das diversas pressões apontadas no estudo.

Embora as condições das linhas de microcrédito sejam hoje mais simplificadas, ainda assim têm sido um empecilho para muitos empreendedores. A burocracia imposta pelas instituições financeiras, como a exigência de fiador e ausência de restrições cadastrais, e as altas taxas de juros têm impedido que mais pessoas se beneficiem desses recursos, em alinhamento ao estudo de Ali et al. (2017).

Corroborando o resultado de outras pesquisas efetuadas sobre o tema, destaca-se que o sucesso do microcrédito no combate à pobreza exige que os modelos de atuação desenvolvidos pelas IMF's sejam desenhados de forma a atingir os mais pobres (Kim, 2017; Yunus, 2009; Silva, Fonseca, \& Santos, 2016). Tal desenho deve contemplar uma adequada definição do público-alvo, notadamente o grupo de baixíssima renda, a 
fim de evitar que usuários não pertencentes a este grupo tenham acesso aos recursos provenientes do microcrédito (Navajas et al., 2000; Loubere, 2016). Nesse sentido torna-se imperiosa a criação de metodologias específicas para análise do risco de crédito do setor microfinanceiro, bem como a definição de um marco legal mais apropriado para as atividades exercidas pelos BCD's e as moedas locais (Rigo, 2014).

Desta forma, conclui-se que o programa implementado na Cidade de Deus não atingiu plenamente o segmento da população excluído pelo mercado bancário tradicional, no período investigado, tendo suas ações aproximado-se mais da perspectiva econômica e da adoção de melhores práticas voltadas para a sustentabilidade das instituições financeiras envolvidas do que perspectiva social (que defende a tese de que os programas de microcrédito deveriam socorrer os mais pobres, concedendo crédito e acompanhando o desenvolvimento do negócio). Este resultado alinha-se ao estudo na China conduzido por Loubere (2016) no qual o microcrédito facilita a "(de)marginalização" de certos indivíduos ou grupos, ao mesmo tempo em que (re)produz desigualdades e exacerba a marginalização de outros.

Outras questões precisam ser igualmente equacionadas, considerando-se o processo de implementação das políticas públicas de geração de emprego e renda, num contexto diversificado como o brasileiro, tais como: as intervenções desenvolvidas e implementadas até então pelo governo federal são, de fato, as mais relevantes para cada contexto local específico? Têm combatido os múltiplos determinantes da pobreza? Há uma convergência desses programas, de forma a integrar as ações? Questões como essas podem se tornar pontos de partida para futuras pesquisas em torno do desenvolvimento do sistema microfinanceiro brasileiro.

\section{REFERÊNCIAS}

Ali, I., Hatta, Z. A., Azman, A., \& Islam, S. (2017). Microfinance as a development and poverty alleviation tool in rural Bangladesh: A critical assessment. Asian Social Work and Policy Review, 11(1), 4-15. doi:10.1111/ aswp.12106

Armstrong, K., Ahsan, M., \& Sundaramurthy, C. (2017). Microfinance ecosystem: How connectors, interactors, and institutionalizers co-create value. Business Horizons, 61(1), 147-155. doi:10.1016/j.bushor.2017.09.014

Banco Central do Brasil. (2015). Relatório de evolução do SFN- BACEN - quadro 1: Quantitativo de instituições autorizadas a funcionar. Recuperado de http://www.bcb. gov.br.

Barone, F. M, Lima, P., Dantas, V., Rezende, V. (2002). Introdução ao Microcrédito, Brasília, DF: Conselho de Comunidade Solidária.

Birochi, R., \& Pozzebon, M. (2016). Improving financial inclusion: Towards a critical financial education framework. RAE-Revista de Administração de Empresas, 56(3), 266287. doi:10.1590/S0034-759020160302

Cárdenas, A. C. P., \& Oliveira, G. B. (2010). Microcrédito e desenvolvimento: Um panorama do caso brasileiro. Revista FAE, 13(1), 29-46.

Cuong, N. V. (2008). Is a governmental micro- 
-credit program for the poor really pro-poor? Evidence for Vietnam. The Developing Economies Journal, 46(2), 151-187. doi:10.1111/ j.1746-1049.2008.00061.x

Diniz, E. H. (2010). Correspondentes Bancários e Microcrédito no Brasil: Tecnologia Bancária e Ampliação dos Serviços Financeiros para a População de Baixa Renda. (Relatório de pesquisa 04/2010). Escola de Administração de Empresas, Fundação Getúlio Vargas. Recuperado de http://bibliotecadigital.fgv.br/dspace/handle/10438/13365.

Duong, P. B., \& Yzumida, Y. (2002). Rural development finance in Vietnam: A microeconometric analysis of household surveys. The World Development, 30(2), 319-335. doi:10.1016/S0305-750X(01)00112-7

Fafchamps, M., McKenzie, D., Quinn, S., \& Woodruff, C. (2014). Microenterprise growth and the flypaper effect: Evidence from a randomized experiment in Ghana. Journal of Development Economics, 106, 211-226. doi:10.1016/j.jdeveco.2013.09.010

Feltrin, L. E., Ventura, E. C. F., \& Dodl, A. V. B. (2009). Inclusão financeira no Brasil - Projeto estratégico do Banco Central. In L. E. Feltrin, E.C. F. Ventura, \& A.V. B. Dodl (Coord). Perspectivas e desafios para inclusão financeira no Brasil: Visão de diferentes autores (pp. 13-26). Brasília, DF: Banco Central do Brasil.

Gerbelli, L. G. (2015, 07 agosto). Trabalho informal predomina no mundo. Estadão. Caderno economia \& negócios, Recuperado de http://economia.estadao.com.br/noticias/ geral,trabalho-informal-predomina-no-mun- do, 1739524 .

Gonzalez-Vega, C. (2000). Uma visão geral das microfinanças. in Seminário internacional BNDES de micro finanças: Ensaios e experiências, Rio de Janeiro, RJ: BNDES.

Gonzalez, L., Porto, L., \& Diniz, E. H. (2017). Microcrédito produtivo no Brasil: Histórico recente e condicionantes de desenvolvimento. Cadernos Gestão Pública e Cidadania, 22(72), 184-204. doi:10.12660/cgpc. v22n72.62637

Gulli, H. (1998). Microfinance and poverty: Questioning the conventional wisdom. Washington, E.U.A: Inter-American Development Bank.

Guérin, I., \& Kumar, S. (2017). Market, freedom and the illusions of microcredit: Patronage, caste, class and patriarchy in rural South India. The Journal of Development Studies, 53(5), 741-754. doi:10.1080/00220388.2016. 1205735

Harper, M. (2001). Profit of the poor: Cases in microfinance. London, UK: ITDG Publishing.

Hemais, M. W., Borelli, F., Casotti, L. M., \& Dias, P. R. C. (2014). Economics, marketing and low income individuals: Interest after a history if indifference. Revista de Ciências da Administração, 16(39), 49-64.

Hulme, D., Dichter, T., Harper, M. (2007). Is microdebt good for poor people? A note on the dark side of microfinance. In What's wrong with Microfinance. Warwickshire: Intermediate Technology Publications. 19-22

Instituto Brasileiro de Geografia e Estatística- 
-IBGE (2014). Pesquisa nacional por amostra de domic ilios - PNAD/2014. Recuperado de http://www.ibge.gov.br/home/estatistica/ populacao/.../pnad2014/.

Kim, D. (2017). Microcredit in Bangladesh and Haiti: Helping poor families to overcome poverty. Global Majority E-Journal, 8(1), 1833.

Ledgerwood, J. (1998). Microfinance handbook: An institutional and financial perspective. Washington, US.: The World Bank.

Liñares-Zegarra, J., \& Wilson, J. O. S. (2017). The size and growth of microfinance institutions. The British Accounting Review, 50(2). https://doi.org/10.1016/j.bar.2017.11.006.

Lønborg, J. H., \& Rasmussen, O. D. (2014). Can microfinance reach the poorest? Evidence from a community managed microfinance intervention. World Development, 64, 460472. doi:10.1016/j.worlddev.2014.06.021

Loubere, N. (2016). Indebted to development: microcredit as (de)marginalisation in rural China. The Journal of Peasant Studies, 45(3), 585-609. doi:10.1080/03066150.2016 .1236025

Marques, V. S., Santos R. R., Siqueira, J. R. M., \& Santos, R. (2011). Microcrédito no Rio de Janeiro: Uma análise do caso BNDES-VIVACRED. Revista de Informação Contábil, 5(3), 31-42.

Mason, D. R. (2014). Who gets what? Determinants of loan size and credit rationing among microcredit borrowers: Evidence from Nicaragua. Journal of International Development, 26(1), 77-90.
Ministério do Trabalho e Emprego (2015). $1^{\circ}$. Plano Nacional de Economia Solidária (2015-2019). Brasília: Conselho Nacional de Economia Solidária. Recuperado de http:// trabalho.gov.br/images/Documentos/EconomiaSolidaria/PlanoNacionalEcoSol.pdf.

Miranda, R. (2011). Microfinanças: Um levantamento bibliográfico sobre o panorama mundial e local sobre a inclusão social através do acesso a serviços financeiros. In XVI SEMEAD - Seminários de Administração.

Navajas, S., Schreiner, M., Meyer, R. L., Gonzalez-Vega, C., \& Rodriguez-Meza, J. (2000). Microcredit and the poorest of the poor: Theory and evidence from Bolivia. World Development, 28(2), 333-346. doi:10.1016/S0305-750X(99)00121-7

Parente, S. (2006). Microfinanças: Saiba o que é um banco do povo. $5^{\mathrm{a}}$ Ed. Brasília, DF: AED.

Passos, O. V. (2007). Estudo exploratório em bancos comunitários: Conceitos, características e sustentabilidade. $139 \mathrm{f}$. (Tese de mestrado). Universidade Federal da Bahia, Escola de Administração, Salvador.

Pereira, A. C., Mross, C., Alves, J. C., Lavorato, \& Aguiar, L. J. B. (2009). Massificação das microfinanças no Brasil: Análise e proposições. In L. N. Feltri, E.C.F. Ventura, \& A. V. B. Dodl. (Coord.), Perspectivas e desafios para inclusão financeira no Brasil: Visão de diferentes autores. Brasília, DF: BCB. 254 p.

Polato, A. (2013). Muhammad Yunus: "Todos somos empreendedores". Revista Épocanegócios e carreira . Edição 783. Recupe- 
Vera Lúcia de Aguiar Kelly - Ana Carolina Pimentel Duarte da Fonseca - Fernanda Filgueiras Sauerbronn

rado de

http://revistaepoca.globo.com/Negocios-e-carreira/noticia/2013/05/muhammad-yunus-todos-somos-empreendedores.html

Prahalad, C. K. (2006). A riqueza na base da pirâmide: Como erradicar a pobreza com o lucro. Porto Alegre, RS: Bookman.

Rede Brasileira de Bancos Comunitários. (2006). Banco comunitário. Serviços financeiros solidários em rede. Fortaleza, CE: Rede de Bancos Comunitários.

Rigo, A. S. (2014). Moedas sociais e bancos comunitários no Brasil: Aplicações e implicações, teóricas e práticas. 339 f. (Tese de doutorado). Universidade Federal da Bahia, Escola de Administração. Salvador.

Rigo, A. S., França Filho, G. C., \& Leal, L. P. (2015). Os bancos comunitários de desenvolvimento na política pública de finanças solidárias: Apresentando a realidade do Nordeste e discutindo proposições. Desenvolvimento em Questão, 13(31), 70-107. doi:10.21527/22376453.2015.31.70-107

Sachs, J. D. (2005). The end of poverty: economic possibilities for our time. New York, NY: Penguin Books.

Santos, A. F. C. D., \& Santos, T. L. (2017). O microcrédito como ferramenta de desenvolvimento socioeconômico. Pensamento \& Realidade, 32(1), 31-40.

Sen, A. (2000). Desenvolvimento como Liberdade. São Paulo, SP: Companhia das Letras.

Silva, W. A. C., Fonseca, R. F., \& Santos, A. O. (2016). Microbusiness development and quality of life of microentrepreneurs's families. Revista de Administração Mackenzie, 17(4), 176-200. doi:10.1590/1678-69712016/administracao.v17n4p176-200

Soares, M. M., \& Sobrinho, A. D. M. (2008). Microfinanças: O papel do Banco Central do Brasil e a importância do cooperativismo de crédito (2 $2^{\mathrm{a}}$ Ed.). Brasília, DF: BCB.

Vasconcelos, D. S. (2006). Microcrédito. Combate a pobreza e desenvolvimento econômico: Uma análise do debate sobre a focalização e sustentabilidade dos programas de microfinanças. Prêmio Ipea 40 anos. Ipea.

Vieira, S. (2011, setembro 15). Cidade de Deus ganha primeiro banco comunitário do Rio de Janeiro. Rede Record, Rio de Janeiro. Recuperado de http://www.noticias.r7.com/ rio-de-janeiro/noticias/cidade-de-deus-ganha-primeiro-banco-comunitario-do-rio-de-janeiro-20110915.html.

Worthen, H. (2012). Women and microcredit: Alternative readings of subjectivity, agency, and gender change in rural Mexico. Gender, Place \& Culture, 19(3), 364-381. doi:10.1080/096636 9X.2011.624740

Yunus, M. (2009). Um mundo sem pobreza. A empresa social e o futuro do capitalismo. São Paulo, SP: Ática.

Zouain, D. M., \& Barone, F. M. (2007). Excertos sobre política pública de acesso ao crédito como ferramenta de combate à pobreza e inclusão social: O microcrédito na era FHC. Revista de Administração Pública, 41(2), 369-380. doi:10.1590/S0034-76122007000200010 